\title{
Pharmacological Treatment of Major Depressive Episodes with Mixed Features: A Systematic Review
}

\author{
In Hee Shim ${ }^{1}$, Won-Myong Bahk', Young Sup Woo ${ }^{2}$, Bo-Hyun Yoon ${ }^{3}$ \\ ${ }^{1}$ Department of Psychiatry, Cancer Center, Dongnam Institute of Radiological \& Medical Sciences, Busan, ${ }^{2}$ Department of Psychiatry, College \\ of Medicine, The Catholic University of Korea, Seoul, ${ }^{3}$ Department of Psychiatry, Naju National Hospital, Naju, Korea
}

\begin{abstract}
We reviewed clinical studies investigating the pharmacological treatment of major depressive episodes (MDEs) with mixed features diagnosed according to the dimensional criteria (more than two or three [hypo]manic symptoms+principle depressive symptoms). We systematically reviewed published randomized controlled trials on the pharmacological treatment of MDEs with mixed features associated with mood disorders, including major depressive disorder (MDD) and bipolar disorder (BD). We searched the PubMed, Cochrane Library, and ClinicalTrials.gov databases through December 2017 with the following key word combinations linked with the word OR: (a) mixed or mixed state, mixed features, DMX, mixed depression; (b) depressive, major depressive, MDE, MDD, bipolar, bipolar depression; and (c) antidepressant, antipsychotic, mood stabilizer, anticonvulsant, treatment, medication, algorithm, guideline, pharmacological. We followed the Preferred Reporting Items for Systematic Reviews and Meta-Analyses guidelines. We found few randomized trials on pharmacological treatments for MDEs with mixed features. Of the 36 articles assessed for eligibility, 11 investigated MDEs with mixed features in mood disorders: six assessed the efficacy of antipsychotic drugs (lurasidone and ziprasidone) in the acute phase of MDD with mixed features, although four of these were post hoc analyses based on large randomized controlled trials. Four studies compared antipsychotic drugs (olanzapine, lurasidone, and ziprasidone) with placebo, and one study assessed the efficacy of combination therapy (olanzapine+fluoxetine) in the acute phase of BD with mixed features. Pharmacological treatments for MDEs with mixed features have focused on antipsychotics, although evidence of their efficacy is lacking. Additional well-designed clinical trials are needed.
\end{abstract}

KEY WORDS: Antipsychotic agents; Bipolar disorder; Major depressive disorder; Mixed features; Pharmacological treatment.

\section{INTRODUCTION}

The mixed features specifier introduced in the fifth edition of the Diagnostic and Statistical Manual of Mental Disorders (DSM-5), it has been changed more dimensionally (more than two or three [hypo]manic symptoms+ principle depressive symptoms) in major depressive episodes (MDEs) of mood disorders. As a result of this change, estimates of the prevalence of episodes with mixed features have varied widely because the definition of this

Received: March 7, 2018 / Accepted: March 12, 2018

Address for correspondence: Won-Myong Bahk, MD, PhD

Department of Psychiatry, Yeouido St. Mary's Hospital, College of

Medicine, The Catholic University of Korea, 10 63-ro,

Yeongdeungpo-gu, Seoul 07345, Korea

Tel: +82-2-3779-1250, Fax: +82-2-780-6577

E-mail: wmbahk@catholic.ac.kr

ORCID: https://orcid.org/0000-0002-0156-2510 specifier has differed across studies. The reported prevalence of MDEs with mixed features has ranged from $46.4 \%$ to $73.1 \%$ in bipolar disorder (BD) and from $7.6 \%$ to $48.7 \%$ in major depressive disorder (MDD). ${ }^{1-6)}$ Mixed features are associated with a more severe clinical course, including earlier onset, frequent recurrence, greater risk of comorbid disorders, longer time to remission, poorer response to pharmacological treatment, and higher suicide risk, compared with pure affective episodes. ${ }^{7,8)}$ Thus, the treatment of MDEs with these clinical features is difficult and requires additional attention.

Despite the clinical severity of MDEs, few studies have investigated pharmacological treatments for this condition or performed only subgroup analyses or post hoc analyses in patients with manic episodes. However, most studies use narrow diagnostic criteria for mixed episodes that include the 4th edition of DSM (DSM-IV) text revision

(ㄷ) This is an Open-Access article distributed under the terms of the Creative Commons Attribution Non-Commercial License (http://creativecommons.org/licenses/by-nc/4.0) which permits unrestricted non-commercial use, distribution, and reproduction in any medium, provided the original work is properly cited. 
criteria for simultaneously meet full criteria for both MDEs and manic episode. ${ }^{9)}$ It is difficult to apply these criteria to MDEs with mixed features because it presents the major polarity for depression and additional (hypo)manic symptoms.

Therefore, we reviewed the evidence for the efficacy of pharmacological treatments according to dimensional criteria for MDEs with mixed features.

\section{METHODS}

\section{Literature Search}

We systematically reviewed published randomized controlled trials (RCTs) of pharmacological treatments for MDEs with mixed features occurring in the course of mood disorders, including MDD and BD. We searched the PubMed, Cochrane Library, and ClinicalTrials.gov databases through December 2017 with the following key word combinations linked with the word OR: (a) mixed, mixed state, mixed features, DMX, mixed depression; (b) depressive, major depressive, MDE, MDD, bipolar, bipolar depression; and (c) antidepressant, antipsychotic, mood stabilizer, anticonvulsant, treatment, medication, algorithm, guideline, pharmacological.

\section{Study Selection}

We followed the Preferred Reporting Items for Systematic Reviews and Meta-Analyses guidelines (PRISMA; Fig. 1). ${ }^{10)}$
Studies that met the following criteria were included in the analysis: 1) published studies of MDEs with mixed features (MDD or BD) using dimensional criteria (more than two or three symptoms with the opposite polarity); 2) studies based on RCTs; and 3) original articles.

\section{RESULTS}

Of the 36 studies assessed for eligibility, 11 (six related to MDD and five related to BD) were included in the analysis. The small number of studies eligible for our analysis demonstrates that pharmacological treatment for MDEs with mixed features that meet DSM- 5 criteria is an understudied area.

Of the studies originally identified, 25 did not meet the inclusion criteria. In those, three was a just conference abstract and 15 were excluded because the aim or design was not appropriate. Furthermore, because our focus was on depression with mixed features, which is largely unstudied, seven studies with inappropriate subgroup allocations were excluded.

\section{Major Depressive Disorder}

The findings related to MDD are shown in Table 1. ${ }^{11-16)}$ The majority of studies of MDD with mixed features have focused on the antipsychotic drugs, lurasidone and ziprasidone. In particular, we found five post-hoc studies of lurasidone based on one backbone study. In the origi-

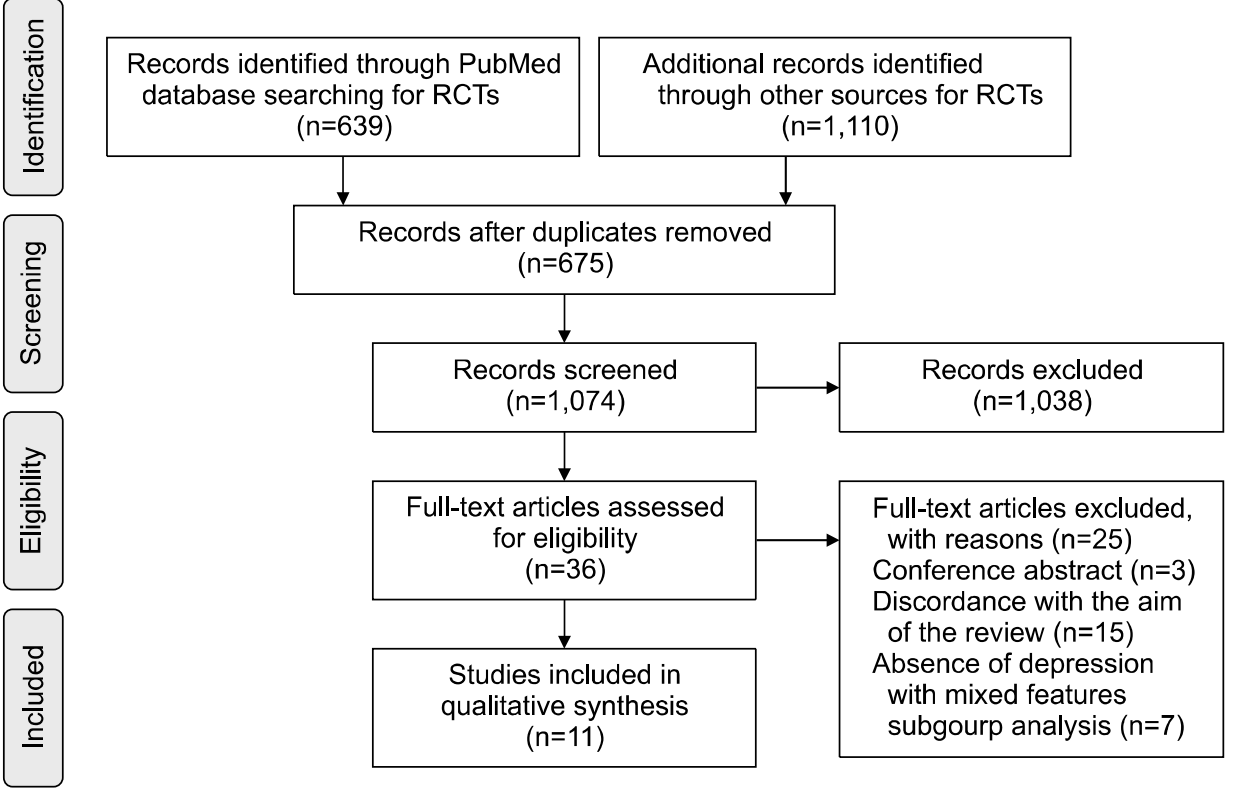

Fig. 1. A flowgram of PRISMA (Preferred Reporting Items for Systematic Reviews and Meta-Analyses). $\mathrm{RCT}$, randomized controlled trial. 
Table 1. Randomized controlled trials in major depressive episode (MDE) with mixed features in major depressive disorders

\begin{tabular}{|c|c|c|c|c|c|c|}
\hline Study & $\begin{array}{l}\text { Duration } \\
\text { (wk) }\end{array}$ & Medication & $\begin{array}{l}\text { Primary } \\
\text { measure }\end{array}$ & Definition & Results & Remark \\
\hline $\begin{array}{l}\text { Suppes et al. }{ }^{11)} \text { (2016) } \\
\text { Post-hoc studies } \\
\text { Tsai et al. }{ }^{12)} \text { (anxiety) } \\
\text { Swann } \text { et al. }{ }^{13)} \text { (irritability) } \\
\text { Sramek et al. }{ }^{14)} \text { (post-menopause) } \\
\text { Goldberg et al. }{ }^{15)} \text { ( } 3 \text { mo extension study) }\end{array}$ & 6 & $\begin{array}{l}\text { Lurasidone } \\
(20-60 \mathrm{mg} / \text { day, } \\
\mathrm{n}=109) \text { vs. } \\
\text { placebo }(\mathrm{n}=100)\end{array}$ & $\begin{array}{l}\text { Changes from } \\
\text { baseline in } \\
\text { MADRS }\end{array}$ & $\begin{array}{l}\text { MDE with 2-3 } \\
\text { manic } \\
\text { symptoms }\end{array}$ & $\begin{array}{c}-20.5 \text { vs. }-13.0 \\
(\text { effect size }=0.80)\end{array}$ & $\begin{array}{l}\mathrm{m} / \mathrm{c} \text { adverse } \\
\text { events: nausea } \\
(6.4 \% \text { vs. } 2.0 \%), \\
\text { somnolence } \\
\text { (5.5\% vs. } 1.0 \%)\end{array}$ \\
\hline Patkar et al. ${ }^{16)}(2015)$ & 13 & $\begin{array}{l}\text { Ziprasidone } \\
\text { (20 mg bid- } \\
160 \mathrm{mg} / \mathrm{d}) \text { vs. } \\
\text { placebo }(\mathrm{n}=49)\end{array}$ & $\begin{array}{l}\text { Changes from } \\
\text { baseline in } \\
\text { MADRS }\end{array}$ & $\begin{array}{l}\text { MDE with at } \\
\text { least } 3 \text { of } \\
\text { bipolarity }\end{array}$ & $\begin{array}{l}\text { Nonsignificant } \\
(-1.57 \pm 1.67 \\
\text { in ziprasidone, } \\
p=0.48)\end{array}$ & Crossover study \\
\hline
\end{tabular}

MADRS, Montgomery-Åsberg Depression Rating Scale; m/c, most common; bid, twice a day.

Table 2. Randomized controlled trials in major depressive episode with mixed features in bipolar disorders

\begin{tabular}{|c|c|c|c|c|c|c|}
\hline Study & $\begin{array}{l}\text { Duration } \\
\text { (wk) }\end{array}$ & Medication & $\begin{array}{l}\text { Primary } \\
\text { measure }\end{array}$ & Definition & Results & Remark \\
\hline $\begin{array}{l}\text { Tohen et al. }{ }^{19)} \\
(2014)\end{array}$ & 6 & $\begin{array}{l}\text { Olanzapine } \\
(\mathrm{n}=690) \text { vs. } \\
\text { placebo }(\mathrm{n}=524)\end{array}$ & $\begin{array}{l}\text { Changes from } \\
\text { baseline in MADRS }\end{array}$ & $\begin{array}{l}\text { BD I depression } \\
\text { with } 0,1 \text { or } 2, \geq 3 \\
\text { manic symptoms }\end{array}$ & $\begin{array}{l}-3.76(p=0.002) \text { vs. }-3.20 \\
(p<0.001) \text { vs. }-3.44(p=0.002) \\
\text { for } 0,1 \text { or } 2, \geq 3 \text { manic symptoms }\end{array}$ & $\begin{array}{l}\text { Post-hoc } \\
\text { analysis }\end{array}$ \\
\hline $\begin{array}{l}\text { Mclntyre et al..20) } \\
(2015)\end{array}$ & 6 & $\begin{array}{l}\text { Lurasidone } 20-120 \\
\text { mg }(n=182) \text { vs. } \\
\text { placebo }(n=90)\end{array}$ & $\begin{array}{l}\text { Changes from } \\
\text { baseline in MADRS }\end{array}$ & $\begin{array}{l}\text { BD I depression } \\
(\text { MADRS } \geq 20, \\
\text { YMRS } \leq 12) \\
\text { with YMRS } \geq 4\end{array}$ & -15.7 vs. $-10.9(p=0.001)$ & $\begin{array}{l}\text { Post-hoc } \\
\text { analysis }\end{array}$ \\
\hline $\begin{array}{l}\text { Patkar et al. }{ }^{21)} \\
\text { Pae } \text { et al. }{ }^{22)} \\
(2012)\end{array}$ & 6 & $\begin{array}{l}\text { Ziprasidone } \\
\text { (40-160 mg/day) } \\
\text { vs. placebo }(\mathrm{n}=72)\end{array}$ & $\begin{array}{l}\text { Changes from } \\
\text { baseline in MADRS }\end{array}$ & $\begin{array}{l}\text { BD II or MDD } \\
\text { with } 2 \text { or } 3 \\
\text { manic criteria }\end{array}$ & $\begin{array}{l}\text { Ziprasidone > placebo ( } p=0.0038) \\
\text { BD II }>\text { MDD }(p=0.036)\end{array}$ & \\
\hline $\begin{array}{l}\text { Benazzi et al. }{ }^{18)} \\
(2009)\end{array}$ & 8 & $\begin{array}{l}\text { Olanzapine }(5-20 \\
\text { mg/day, } n=351) \\
\text { vs. OFC }(6 / 25, \\
6 / 50,12 / 50 \\
\text { mg/day, } n=82) \text { vs. } \\
\text { placebo }(n=355)\end{array}$ & $\begin{array}{l}\text { Response }(\geq 50 \% \\
\text { reduction) in } \\
\text { MADRS and }<2 \\
\text { concurrent } \\
\text { (hypo)manic } \\
\text { symptoms }\end{array}$ & $\begin{array}{l}\text { BD I depression } \\
\text { with } \geq 2 \text { manic } \\
\text { symptoms }\end{array}$ & $\begin{array}{l}\text { OFC vs. olanzapine: OR=2.00 } \\
\text { (95\% Cl, 0.96-4.19); OFC vs. } \\
\text { placebo: OR=3.91 (95\% Cl, } \\
\text { 1.80-8.49); olanzapine vs. } \\
\text { placebo: OR=1.95 (95\% Cl, } \\
\text { 1.14-3.34) }\end{array}$ & $\begin{array}{l}\text { Post-hoc } \\
\text { analysis }\end{array}$ \\
\hline
\end{tabular}

MADRS, Montgomery-Åsberg Depression Rating Scale; BD, bipolar disorder; YMRS, Young Mania Rating Scale; MDD, major depressive disorder; OFC, olanzapine+fluoxetine; OR, odds ratio; $95 \% \mathrm{Cl}, 95 \%$ confidence interval.

nal study, patients were randomly assigned to 6 weeks of double-blind treatment with lurasidone (20-60 mg/day, $\mathrm{n}=109)$ or placebo $(\mathrm{n}=100){ }^{11)}$ Lurasidone significantly improved the severity of the depressive symptoms compared with their baseline levels according to the Montgomery-Åsberg Depression Rating Scale (MADRS; -20.5 vs. -13.0 , respectively; effect size $=0.80$ ) and the Clinical Global Impression Scale (CGl; -1.5 vs. -1.2, respectively; effect size $=0.60)$ scores. Moreover, the assessment of manic symptoms, a mixed feature associated with MDD, using the Young Mania Rating Scale (YMRS) revealed significant improvement after the 6-week course of lurasidone. The incidence of side effects was similar to that associated with the placebo $(40.4 \%$ vs. $38.0 \%$, respectively), with nausea and somnolence reported to be the major side effects. ${ }^{11)}$

Two studies investigated the primary end points associated with anxiety and irritability, which are major symptoms of MDE with mixed features. Tsai et al. ${ }^{12)}$ assessed the effect of lurasidone on baseline anxiety. The Hamilton Anxiety Rating Scale (HAM-A) was used to identify patients with mild anxiety (HAM-A, $\leq 14)$ and moderateto-severe anxiety (HAM-A, $\geq 15$ ) at baseline. Lurasidone treatment was associated with significant improvement 
(vs. placebo) in patients with mild $(-7.6$ vs. -4.0 , respectively; $p<0.01$, effect size $=0.62$ ) and moderate-tosevere $(-11.4$ vs. -6.1 , respectively; $p<0.0001$, effect size $=0.91)$ anxiety. Swann et al. ${ }^{13)}$ found that lurasidone significantly improved depressive symptoms in patients with and without irritability as measured by the irritability and disruptive aggression items on the YMRS. Moreover, compared with placebo, lurasidone significantly reduced irritability in those with MDE with mixed features with irritable features (irritability item: -1.4 vs. -0.3 , respectively; $p=0.0012$, effect size $=1.0$; disruptive-aggressive item: -1.0 vs. -0.3 , respectively; $p=0.0002$, effect size $=$ 1.2). ${ }^{13)}$

Menopause is an important clinical variable of MDEs with mixed features. In a post-hoc study, Sramek et al. ${ }^{14)}$ found that lurasidone was an effective treatment for patients with post-menopausal MDD with mixed features ( $p=0.0056$, effect size $=0.96$ ).

A post-hoc analysis of a RCT with an open-label extension of lurasidone assessed remission and recovery in patients with MMD with mixed features using the MADRS and Sheehan Disability Scale scores. ${ }^{15)}$ Compared with those who received placebo, a significantly higher proportion of patients treated with lurasidone achieved recovery at week 6 (assessed crosssectionally), and this was sustained at 1 and 3 months. Furthermore, the sustained recovery rate was higher in the lurasidone-to-lurasidone $(20.8 \%)$ than the placebo-to-lurasidone $(12.5 \%)$ arm of the extension study.

In a double-blind, prospective, 13-week crossover trial, patients with bipolar spectrum disorder were randomly assigned to a ziprasidone-washout-placebo or a placebo-washout-ziprasidone group. The authors found that ziprasidone (MADRS score change of $-1.57 \pm 1.67 ; p=0.48$ ) was not more effective than placebo. ${ }^{16)}$ Although this study may be controversial in terms of its use of bipolar spectrum disorder, the criteria for distinguishing bipolarity in MDD reflect most of the characteristics of MDD with mixed features. Moreover, the view that the mixed features specifier for MDD represents a structural bridge between MDD and BD recognizes that bipolar spectrum disorder is similar to MDD with mixed features. ${ }^{17)}$

\section{Bipolar Disorder}

The principle pharmacological treatments for MDEs with mixed features associated with BD are olanzapine/ olanzapine+fluoxetine (OFC), lurasidone, and ziprasidone (Table 2).

In a post-hoc study based on an 8-week trial, Benazzi et al. ${ }^{18)}$ compared the responses to olanzapine $(5-20 \mathrm{mg} / \mathrm{d}$; $\mathrm{n}=351)$, OFC $(6 / 25,6 / 50,12 / 50 \mathrm{mg} / \mathrm{d} ; \mathrm{n}=82)$, and placebo $(n=355)$ in patients with BD I depression with two or more manic symptoms. A therapeutic response was defined as a $\geq 50 \%$ reduction in the MADRS score and $<2$ concurrent hypo/manic symptoms. The authors concluded that OFC may be an effective treatment for BD I depression with mixed features, although the difference in efficacy between OFC and olanzapine monotherapy was not statistically significant (OFC vs. olanzapine: odds ratio $[\mathrm{OR}]=2.00$, 95\% confidence interval $[\mathrm{Cl}], 0.96-4.19$; OFC vs. placebo: $\mathrm{OR}=3.91,95 \% \mathrm{Cl}, 1.80-8.49$; olanzapine vs. placebo: $\mathrm{OR}=1.95,95 \% \mathrm{Cl}, 1.14-3.34) .{ }^{18)}$

A recent study measured changes in the MADRS score from baseline to 6 weeks to compare the effects of olanzapine $(n=690)$ and placebo $(n=524)$ on the number of concurrent manic symptoms in patients with BD I depression with mixed features. ${ }^{19)}$ The change in the MADRS score was significantly greater in the olanzapine than in the placebo group, irrespective of the number of manic symptoms $(-3.76, p=0.002 ;-3.20, p<0.001$; and -3.44 , $p=0.002$ for 0,1 or 2 , and $\geq 3$ mixed features, respectively). ${ }^{19)}$

Similar to those examining MDD with mixed features, several RCTs have assessed the efficacy of lurasidone for the treatment of BD I depression with mixed features. One study found that mixed features were present in $56 \%$ of the patients with BD I at baseline, and treatment with lurasidone (vs. placebo) significantly reduced MADRS scores in this group $(-15.7$ vs. -10.9 , respectively; $p=0.001$; week 6 ; mixed model for repeated measures; effect size $=0.48) .{ }^{20)}$ Moreover, in terms of safety and tolerability, the incidence of adverse events associated with lurasidone that were reported by at least $5 \%$ of the participants was higher in the group with mixed features than in those without mixed features (nausea: $16.1 \%$ vs. $11.0 \%$, respectively; and akathisia: $12.4 \%$ vs. $5.5 \%$, respectively). However, the risk of treatment-emergent hypomania or mania was not increased. ${ }^{20)}$

An investigation of the efficacy of ziprasidone in patients with MDEs with mixed features associated with BD II and MDD found that the change in the MARDS change from baseline was greater in the ziprasidone than in the 
placebo group ( $p=0.0038$ ) and that the effect was more pronounced in the BD II compared to the MDD group. ${ }^{211}$ In terms of safety and tolerability, no significant changes were observed in weight, akathisia, extrapyramidal symptoms, or incidence of headache/drowsiness. A subsequent study conducted to identify predictors associated with the response to ziprasidone or remission in patients with mixed depressive states found no predictor variables. ${ }^{22)}$

\section{DISCUSSION}

We reviewed clinical studies of pharmacological treatments for MDEs with mixed features associated with MDD and BD diagnosed according to DSM-5 criteria. However, the criteria for the DSM- 5 mixed-features specifier differ from those for the DSM-IV mixed-episode criteria, and most studies of mixed features have focused on mania (mixed mania) rather than on depression (depressive mixed state). As a result, our analysis included only 11 studies.

Atypical antipsychotics are the mainstay of the pharmacological treatment for MDEs with mixed features. Our findings are consistent with those of a previous study that found that atypical antipsychotics were a more effective treatment for depressive symptoms with mixed episodes than was placebo, although their diagnoses were based on the DSM-IV text revision criteria for "mixed episodes (co-occurrence of full mania and full MDEs). ${ }^{\text {"23) }}$ Among lurasidone related to studies, Nelson et al. ${ }^{24)}$ reported that lurasidone improved depression regardless of baseline depression severity. Additionally, Pikalov et al. ${ }^{25)}$ found that it significantly improved manic and depressive symptoms and that the efficacy of the drug was moderated by the characteristics of the manic symptoms. However, because these findings were unpublished poster abstracts, they were not included in our study. The findings of numerous studies on the efficacy of antipsychotics for the treatment of mood disorders support guidelines recommending the use of atypical antipsychotic monotherapy (lurasidone, asenapine, quetiapine, quetiapine extended release, aripiprazole, and ziprasidone) as the first line of treatment for mixed depression. ${ }^{26}$

Large clinical studies of antidepressants and mood stabilizers or of combination therapies are lacking. Based on the findings of observational studies, antidepressants appear to be less effective for mixed states than for pure de- pression (MDEs with no manic symptoms). ${ }^{27)}$ Expert consensus guidelines warn that the monotherapy of antidepressants for MDEs with mixed features may exacerbate subthreshold manic symptoms that accompany depression. ${ }^{26,28,29)}$ However, the most recent pharmacological treatment guideline for mixed features associated with MDD recommend 4- to 8-week trial of an adequate dose of antidepressant monotherapy and assessed subsyndromal hypomania related to the therapeutic outcomes as the initial treatment. ${ }^{30)}$ Given the paucity of systematic studies of antidepressants in patients with mixed features associated with MDD according to DSM-5 criteria, considering the clinical situation and the risk/benefit ratio, there was not sufficient evidence to prevent the use of antidepressants.

Treatment guidelines also recommend monotherapy with mood stabilizers, including lithium, lamotrigine, and valproate, or mood stabilizers in combination with antipsychotics as the first or second lines of treatment. These recommendations are supported by a previous study that found that divalproex with adjunctive olanzapine produced a greater and earlier reduction in manic and depressive symptoms in mixed-episode patients compared to placebo. ${ }^{31)}$ Mood stabilizers are widely used in the acute and maintenance phases of treatment despite insufficient evidence for their clinical use in patients with BD with depression with or without mixed features. Furthermore, the use of mood stabilizers has been shown to be a practical treatment strategy for MDD because the mixed-features specifier is associated with a decreased response to conventional antidepressant treatment and with a possible bipolar spectrum disorder.

Interestingly, improvement of (hypo)manic symptoms rather than of the main symptoms of depression may contribute to the enhancement of the response to treatment. Goldberg et al. ${ }^{15)}$ found that the number of manic symptoms among those with MDD at baseline was a significant moderator of cross-sectional recovery at week 6 (two manic symptoms: $36.4 \%$ vs. $8.2 \%$, number needed to treat $[\mathrm{NNT}]=4$; three manic symptoms: $22.5 \%$ vs. $18.9 \%$, NNT $=28$ ). Moreover, an investigation of OFC efficacy, found that a higher number of concurrent (hypo)manic symptoms at baseline predicted a lower response rate in the olanzapine and placebo arms, but not in the OFC arm of the study. ${ }^{18)}$ This may mean that the poor response to conventional pharmacological treatment, which depends 
on the severity of mixed features. Controlled trials are needed to further investigate monotherapies and combination therapies with the various antipsychotics and mood stabilizers associated with improved manic symptoms.

Our study has several limitations. First, we may have omitted a number of relevant studies (observational studies, unpublished studies, reviews, or case reports) because only published original articles were included in this study. Second, given the relatively small number of evidence-based studies available, we lacked the power to offer clear clinical recommendations.

In conclusion, few studies have investigated pharmacological treatments for patients with MDEs with mixed features, and treatment guidelines also contain on a number of empirical grounds. Most of the studies we identified focused on antipsychotic drugs, whereas controlled trials of antidepressants and mood stabilizers were lacking. Antipsychotics, such as lurasidone, ziprasidone, and olanzapine/OFC, were effective for patients with MDEs with mixed features. Although, the use of antidepressants alone is controversial according to the guidelines, it is necessary to screen for clinical characteristics, such as bipolarity, and assess exacerbation of the (hypo)manic symptoms associated with MDD. Moreover, improvement of the (hypo)manic symptoms associated with MDEs with mixed features may be a more important parameter for prognosis and treatment than the dichotomy between MDD and BD. Further research on pharmacological treatments for MDEs with mixed features is needed.

\section{REFERENCES}

1. Akiskal HS, Benazzi F. Family history validation of the bipolar nature of depressive mixed states. J Affect Disord 2003;73: 113-122.

2. Akiskal HS, Benazzi F. Validating Kraepelin's two types of depressive mixed states: "depression with flight of ideas "and" excited depression”. World I Biol Psychiatry 2004;5:107-113.

3. Benazzi F. Depressive mixed states: unipolar and bipolar II. Eur Arch Psychiatry Clin Neurosci 2000;250:249-253.

4. Benazzi F. Depressive mixed state: testing different definitions. Psychiatry Clin Neurosci 2001;55:647-652.

5. Benazzi F. Mixed states in bipolar II disorder: should full hypomania always be required? Psychiatry Res 2004;127: 247-257.

6. Benazzi F, Akiskal HS. Delineating bipolar // mixed states in the Ravenna-San Diego collaborative study: the relative prevalence and diagnostic significance of hypomanic features dur- ing major depressive episodes. I Affect Disord 2001;67: 115-122.

7. Shim IH, Woo YS, Jun TY, Bahk WM. Mixed-state bipolar I and I/ depression: time to remission and clinical characteristics. J Affect Disord 2014;152-154:340-346.

8. Muneer A. Staging models in bipolar disorder: a systematic review of the literature. Clin Psychopharmacol Neurosci 2016; 14:117-130.

9. American Psychiatric Association. Diagnostic and statistical manual of mental disorders, 4th ed, text revision. Wasington, DC:American Psychiatric Association;2000.

10. Liberati A, Altman DG, Tetzlaff J, Mulrow C, Gøtzsche PC, Ioannidis JP, et al. The PRISMA statement for reporting systematic reviews and meta-analyses of studies that evaluate health care interventions: explanation and elaboration. PLoS Med 2009;6:e1000100.

11. Suppes T, Silva R, Cucchiaro J, Mao Y, Targum S, Streicher C, et al. Lurasidone for the treatment of major depressive disorder with mixed features: a randomized, double-blind, placebo-controlled study. Am J Psychiatry 2016;173:400-407.

12. Tsai J, Thase ME, Mao Y, Ng-Mak D, Pikalov A, Loebel A. Lurasidone for major depressive disorder with mixed features and anxiety: a post-hoc analysis of a randomized, placebo-controlled study. CNS Spectr 2017;22:236-245.

13. Swann AC, Fava M, Tsai J, Mao Y, Pikalov A, Loebel A. Lurasidone for major depressive disorder with mixed features and irritability: a post-hoc analysis. CNS Spectr 2017;22: 228-235.

14. Sramek J, Loebel A, Murphy M, Mao Y, Pikalov A, Cutler NR. Lurasidone in post-menopausal females with major depressive disorder with mixed features: post-hoc analysis of a placebo-controlled trial. Prog Neuropsychopharmacol Biol Psychiatry 2017;78:12-17.

15. Goldberg J, Mao Y, Siu C, Tsai J, Pikalov A, Calabrese J, et al. Lurasidone for the treatment of major depressive disorder with mixed features: do manic symptoms moderate treatment response? Neuropsychopharmacology 2016;41:S515-S516.

16. Patkar AA, Pae CU, Vöhringer PA, Mauer S, Narasimhan M, Dalley $\mathrm{S}$, et al. A 13-week, randomized double-blind, placebo-controlled, cross-over trial of ziprasidone in bipolar spectrum disorder. J Clin Psychopharmacol 2015;35:319-323.

17. Suppes T, Ostacher M. Mixed features in major depressive disorder: diagnoses and treatments. CNS Spectr 2017;22: 155-160.

18. Benazzi F, Berk M, Frye MA, Wang W, Barraco A, Tohen M. Olanzapine/fluoxetine combination for the treatment of mixed depression in bipolar I disorder: a post hoc analysis. I Clin Psychiatry 2009;70:1424-1431.

19. Tohen M, Kanba S, Mclntyre RS, Fujikoshi S, Katagiri H. Efficacy of olanzapine monotherapy in the treatment of bipolar depression with mixed features. J Affect Disord 2014; 164:57-62.

20. McIntyre RS, Cucchiaro J, Pikalov A, Kroger H, Loebel A. 
Lurasidone in the treatment of bipolar depression with mixed (subsyndromal hypomanic) features: post hoc analysis of a randomized placebo-controlled trial. J Clin Psychiatry 2015; 76:398-405.

21. Patkar A, Gilmer W, Pae CU, Vöhringer PA, Ziffra M, Pirok E, et al. A 6 week randomized double-blind placebo-controlled trial of ziprasidone for the acute depressive mixed state. PLoS One 2012;7:e34757.

22. Pae CU, Patkar AA, Gilmer W, Holtzman N, Thommi SB, Ghaemi SN. Predictors of response to ziprasidone: results from a 6-week randomized double-blind, placebo-controlled trial for acute depressive mixed state. Pharmacopsychiatry 2012;45:152-155.

23. Muralidharan K, Ali M, Silveira LE, Bond DJ, Fountoulakis KN, Lam RW, et al. Efficacy of second generation antipsychotics in treating acute mixed episodes in bipolar disorder: a meta-analysis of placebo-controlled trials. I Affect Disord 2013;150:408-414.

24. Nelson C, Tsai J, Mao Y, Pikalov A, Loebel A. Lurasidone for major depressive disorder with mixed features: effect of baseline depression severity on clinical outcome. Eur Neuropsychopharmacol 2016;26(Suppl):S400-S401.

25. Pikalov A, Goldberg J, Mao Y, Siu C, Tsai J, Calabrese J, et al. Lurasidone for the treatment of major depressive disorder with mixed features: do manic symptoms moderate treatment re- sponse? Eur Psychiatry 2017;41 Suppl:S243.

26. Stahl SM, Morrissette DA, Faedda G, Fava M, Goldberg JF, Keck $\mathrm{PE}$, et al. Guidelines for the recognition and management of mixed depression. CNS Spectr 2017;22:203-219.

27. Pae CU, Vöhringer PA, Holtzman NS, Thommi SB, Patkar A, Gilmer W, et al. Mixed depression: a study of its phenomenology and relation to treatment response. I Affect Disord 2012;136:1059-1061.

28. Seo JS, Bahk WM, Wang HR, Woo YS, Park YM, Jeong JH, et al. Korean Medication Algorithm for Depressive Disorders 2017: third revision. Clin Psychopharmacol Neurosci 2018; 16:67-87.

29. Wang HR, Bahk WM, Seo JS, Woo YS, Park YM, Jeong JH, et al. Korean medication algorithm for depressive disorder: comparisons with other treatment guidelines. Clin Psychopharmacol Neurosci 2017;15:199-209.

30. McIntyre RS, Suppes T, Tandon R, Ostacher M. Florida best practice psychotherapeutic medication guidelines for adults with major depressive disorder. I Clin Psychiatry 2017;78: 703-713.

31. Houston JP, Tohen M, Degenhardt EK, Jamal HH, Liu LL, Ketter TA. Olanzapine-divalproex combination versus divalproex monotherapy in the treatment of bipolar mixed episodes: a double-blind, placebo-controlled study. J Clin Psychiatry 2009;70:1540-1547. 